\title{
Integrating philosophy of science in civil engineering: an integrative course design strategy
}

\author{
Miles MacLeod ${ }^{1}$
}

Received: 20 January 2021 / Accepted: 6 October 2021 /Published online: 2 November 2021

(c) The Author(s) 2021

\begin{abstract}
Many philosophers of science think scientific practice can benefit from philosophical concepts, and as such philosophy of science should play a direct role in science and engineering education. In this paper we consider a highly integrative course design strategy for integrating philosophy of science in specific disciplinary educational programmes through adaptation, operationalization and embedding of philosophy of science material to fit both the scientific and educational structure of a programme. The goal of the strategy is to help encourage students to recognize the value of philosophical concepts to scientific decision making and to apply them in their own scientific practice. We use the example of a 7.5 ECTS civil engineering course which implements this design at a European technical university, to elaborate these concepts, and present some evidence on how students receive the course. We discuss some of challenges and limitations of implementing this kind of strategy for teaching philosophy of science.
\end{abstract}

\section{Introduction}

Philosophers of science generally consider there to be a clear role for philosophical concepts in improving the scientific reasoning and practices of scientists and engineers, and accordingly that philosophy of science courses should be required as part of scientific education (see for instance Grayson, 2006). However convincing both scientific departments and students of what is seemingly clear to us can be distinctly challenging (Höttecke \& Silva, 2011). There are no doubt many reasons explaining why the relevance of philosophy of science to scientific practice and

This article belongs to the Topical Collection: Teaching philosophy of science to students from other disciplines

Guest Editors: Sara Green, Joeri Witteveen

Miles MacLeod

m.a.j.macleod@utwente.nl

1 Philosophy Section, University of Twente, Drienerlolaan 5, 7522DN, NB, Enschede, The Netherlands 
scientific education is not always readily perceived (see Grüne-Yanoff, 2014), but in this paper we address a few potential explanations; namely, 1) that philosophy of science is foremost an abstract discipline typically structured around abstract argumentation, conceptual analysis and essay writing, which is quite at a distance from the emphasis on problem-driven learning and concrete methodological acquisition which characterize modern scientific and engineering education; 2) that philosophy of science tends to focus on only a small set of scientific domains, namely physics and biology, and neglect many including almost all of engineering; and 3) that philosophy of science courses - like ethics courses - are typically offered as "general education" courses needing to be generic enough to be meaningful to multiple scientific and engineering programmes simultaneously. This, plus the large number of students such classes often involve, restricts the ability of instructors to motivate the relevance of philosophy of science to individuals.

These factors suggest that one potential pathway to developing the role of philosophy of science within scientific and engineering programmes, particularly the relevance of philosophical concepts to the scientific practice of students, is greater integration of philosophy of science within individual programmes. Integration can mean more than just having courses employ relevant examples or cases from fields being taught, although this is important, but having courses which also fit the educational structure of those programmes, and also fit the educational stage and context at which those courses are taught. The aim of this paper is to outline a model or strategy for integration which attempts to overcome the three obstacles mentioned above using a case example of a course for civil engineering students. This civil engineering course has been taught over the past five years at the University of Twente, a technical university in the Netherlands, as a 7.5 ECTS course. ${ }^{1}$ The strategy guiding the design of the course has developed over the past five years and has three central components. Firstly it relies on adaptation; the selection, development and reconceptualization of philosophy of science material to fit the specific discipline. Secondly, operationalization; namely that philosophical concepts are to some degree rethought and re-structured such that they can be implemented as practical tasks and exercises. Thirdly course content should be embedded in the overall educational structure of their programmes by taking up the educational elements and educational design of that structure. In this paper we discuss how this strategy is implemented in this civil engineering course, and present some limited data on how this strategy meets student perceptions. In discussion, we address some limitations and other considerations we should have when implementing or pursuing this kind of instrumentalizing strategy.

\footnotetext{
${ }^{1}$ ECTS is the standardized European system for calculating study load. One ECTS translates to $28 \mathrm{~h}$ of study.
} 


\section{Applying the integrative design strategy to a civil engineering course}

We begin with description of the basic features of this course and the specific methods used to implement adaptation, operationalization and embedding. To begin with it is important to describe the context in which this strategy was developed insofar as this course was developed as a response to this specific context.

\subsection{The RESTS Programme}

In 2015 the University of Twente introduced what has come to be known as RESTS (Reflection on Science, Technology and Society) teaching. The point of RESTS teaching, as described in internal documents, is to provide students "the ability to reflect critically and systematically on one's assumptions and methods, and on the impact of one's work ...... RESTS includes ethicists of science and technology, philosophers of technology, philosophers of science, historians of science and technology, and science and technology studies researchers. In practical terms all bachelor programmes at the university are required to integrate at least 15 ECTS of RESTS subjects into their programmes. Two main principles have been pursued in this regard. Firstly individual fields choose the RESTS subjects they find most relevant and engaging, and any course is then developed as a unique module for that field or discipline alone. Secondly it was considered by the organizers of the RESTS programme that the best time for intervention of RESTS topics would occur during the penultimate quartile of the bachelor degrees in which students are in the process of preparing bachelor thesis topics. Both aspects in practice form part of the imperative for creating highly integrative philosophy of science courses and the impossibility of relying a standard or textbook-heavy philosophy of science course which works through canonical issues such as confirmation theory or the realism debate. Both students' and programme directors' strong expectations are that whatever RESTS teachers contribute will provide concrete skills expressed as concrete learning goals (as all previous courses in their programmes have), and these skills will be useful for providing better thesis outcomes.

\subsection{Civil engineering: Production of knowledge -content}

Currently the course runs twice a year (one main course and one catch-up) course as part of Module 11, the second last quartile of the bachelor's degree. The course is taught contemporaneously with a 7.5 ECTS contribution from STS (Science and Technology Studies), which faces the same integrative expectations. Current learning goals for the course can be found in Table 1 below.

The course takes place over 10 sessions (in the form of seminars). Seminars are given the by instructor. They involve a lecture on the themes of the seminar interspersed with three or four $10 \mathrm{~min}$ in-class activities. These activities are performed in small groups and include discussion tasks (on a scientific case) and problem-solving 
Table 1 Civil engineering course learning goals. These learning goals have been applied since 2018

1. Describe and explain central philosophical and scientific concepts used to analyze and evaluate scientific practice. Students will acquire a basic vocabulary (concepts and theories) that enables us to talk generally about scientific knowledge. These concepts include "paradigm", "values", "bias", "robustness", "models as technologies", "control".

2. Apply these concepts to analyze and evaluate current practices in civil engineering and their own bachelor thesis practices. Students will identify the many different philosophical, societal and historical perspectives one can have on science and engineering that go beyond images of scientific reasoning as a hard analytical or methodological pursuit. Students will reflect on the nature and reliability of scientific knowledge and explanation.

3. Identify basic forms of logical reasoning and apply them to scientific contexts: Students will distinguish and apply deductive, inductive, abductive, falsificationist, causal and hypothetico-deductive reasoning. Students will further explain the limits of trying to encapsulate scientific reasoning as logical reasoning alone.

4. Deconstruct a model into its essential functional elements and apply this deconstruction to critically evaluate that model and describe its role in a given research context. Students will identify the crucial deeper roles of models and modelling in scientific research as basic elements scientific thinking and reasoning. Students will learn how model-based reasoning is applied in practice to manage problem-solving tasks.

5. Correctly identify the affordances and constraints of observational versus experimental methods in different situations. Students will be able to critically evaluate a given choice in a given context.

6. Identify issues, difficulties and challenges which distinguish a text-book image of scientific research from one that actually occurs in practice: these include the role of values in methodological choices, uncertainties in various methodologies and engineering practices.

tasks (such as logic exercises, see below). For some sessions students are required to read sections of Barker and Kitcher (2014) - a short textbook which covers basic issues concisely, and grounds its discussions in scientific practice. For other parts they read papers from philosophy of science and some papers written by engineers reflecting on engineering. For reading materials students are required to produce a reflection statement of 300 to 500 words which reflects on the relevance of the material for civil engineering and their own practices (50\% of the final grade). Students are also assessed via various project tasks (25\% in total; see examples below) which test the ability of students to put philosophical concepts into their own practice, and an exam worth $25 \%$ which mostly tests the ability of students to accurately describe the concepts they have studied. After their bachelor thesis they are also required to complete a thesis "evaluation task" (see below). In what follows we discuss how the course's current design implements adaptation, operationalization and embedding as means of integration.

Adaptation: With respect to adaption it is clear from the governing educational context - students preparing a bachelor thesis - that teaching a traditional text-book based philosophy of science course, is infeasible. And indeed over the five years the amount of content used in the course which might be said to be canonical philosophy of science has actually decreased. For example traditional discussions over the nature of scientific explanation, confirmation theory and the realism of scientific theories have all been removed save for their brief discussion in Barker and Kitcher (2014). 
The central lesson from the past five years is that the most important aspect for adapting philosophy of science to an individual field is to understand the methodological structure of the field and it's key methodological issues in order to find meeting points between the field, and concepts and theories in philosophy of science. This means in this case, naturally enough, developing a good understanding of civil engineering itself which is not a field philosophy of science has said anything particularly about. Such an investigation in the case of civil engineering reveals that, as opposed to other kinds of engineering fields, civil engineering is remarkably diverse in its methodological practices. Some students will end up using large-scale modeling systems of say water run-off systems or river flows during drought scenarios, others however will be doing basic social science research surveying say biking preferences in order to optimize a bike lane system. Some will do more basic physical experiments on say river silting. This provides an important hook for any philosophical reflection on methodology, given civil engineers are likely throughout their careers to face substantial methodological choices when approaching problems. Being capable of doing this without "availability biases" requires awareness of the affordances and purposes, and constraints, of all kinds of methodologies. As such, in order to motivate the value and relevance of the course to civil engineering students, the students are told at the outset that philosophy of science provides conceptual resources for reflection on methodological choices and decision making, and thus for making informed and justifiable choices in civil engineering. At the same time the students are receiving a Bachelor of Science in Civil Engineering, rather than a Bachelor of Engineering, and although students have already engaged with many scientific techniques, students have not received any explicit discussion on what constitutes scientific reasoning by this point in their degree, and on the differences between different forms, such as hypothetico-deductive and abductive reasoning.

To meet then these learning targets philosophy of science is framed in the course around two principal contributions - reasoning and reflection. In the course handout these two basic learning areas are described as follows.

1. Reasoning: more basic methodological skills and methodological concepts required in scientific practice - resources students can apply directly in their thesis (see particularly learning goals 1, 3, 4 and 5: Table 1).

2. Reflection: philosophical concepts valuable for critically reflecting on, and evaluating, methodological practices, choices and decisions. (see particularly learning goals 1, 2, 4 and 6: Table 1).

The course is then broken into two parts. The first 5 sessions covering reasoning, the second 2 reflection, with two sessions for introduction and conclusion, another for explaining and teaming up individuals for the paradigm task (see below). With respect to the reasoning part the course covers basic forms of scientific reasoning - induction, deduction, abduction and H-D reasoning, as well as falsification. Students are asked to acquire some basic formal deductive logic to ground these concepts and to perform logic exercises, but mostly the focus 
is on treating these logical forms as basic models underlying scientific reasoning and argumentation. We cover their limitations, and standards for reliability, which are different in the case say of abduction versus induction. This part of the course also addresses basic causal-reasoning, particularly the Millian methods (e.g. method of difference) while discussing basic challenges to causal reasoning (such correlation vs causation), but not more abstract discussions on the nature of causation or causal relations in science (such as Woodward's interventionist theory of causation; Woodward, 2005). Students are asked to do causal reasoning exercises, many derived and adapted from Kelley (2013). Thirdly one seminar is dedicated to modeling practices and one seminar to experimentation and observational studies. The modeling seminar deals principally with modeling concepts, model construction and model evaluation, and does cover some more reflective theories on modeling such as a chapter from Morgan and Morrison's Models as Mediators (Morgan \& Morrison, 1999), the B\&K theory of model structure (Knuuttila \& Boon, 2011) and Wimsatt's reductionistic heuristics in modeling (Wimsatt, 2007); but much material aims at developing knowledge of important modeling concepts - such as distinguishing validation and verification, identifying abstractions and idealizations in models or identifying parameter overfitting vs underfitting, explanations of which do not require drawing on current philosophy of science substantially. More abstract discussion or debate about modeling (such as say semantic views or inferential accounts) are not included, but the aim is that students nonetheless at the end have a more nuanced understanding of how models are produced and what their limitations are regardless, which can guide their own decision-making. Finally the session on experiment and observation studies works through basic concepts of experiment and observation, such as control, blinding, biases and so on. Not much is contributed here from philosophy of science literature directly, except for some discussion on types or goals of experimentation. Indeed much of this material focuses on more basic scientific skills and knowledge, but by teaching this as part of "philosophy of science", we help 1) adapt the material to fit students' needs - many of the concepts they have never encountered - and 2) signal the relevance of philosophy of science by positioning it as the source of both basic and advanced critical concepts for evaluating scientific practices.

In the reflection part only two seminars are given. One addresses paradigms, and the other addresses values. These are chosen as the two most relevant philosophical topics for civil engineers for adapting the course. Civil engineers deal with multiple potential paradigmatic scientific structures within their fields and in an age of sustainability and interdisciplinarity there are constant and genuine questions to be asked about the relevance and legitimacy of many current civil engineering approaches. These issues can be captured and understood using the paradigm concept. Indeed a useful paper is available casting current sewerage engineering as stuck in a particularly deep technological paradigm (see Beder, 1997). Additionally for civil engineers the notion that values may play a large or strong role in say scientific evaluation or methodological choice is not unintuitive given the fact that civil engineers have a close engagement with societal issues and concerns, and with governmental and corporate stakeholders. Students are asked to read papers critical of 
current civil engineering strategies in terms of the values underlying these strategies such as Newberry (2010). Students are also asked to read relevant chapters from Barker and Kitcher (2014) which engages well with interesting real world case and issues. The goal as mentioned is to give students potential resources for recognizing, justifying, and reporting limitations in, their own methodological decision-making during their bachelor thesis but also throughout their careers. From reading this material students should gain valuable resources for articulating what might be the reasons why civil engineering at times resists say sustainability initiatives on more methodological or epistemological grounds in traffic engineering or water management. The examples chosen to illustrate philosophical concepts and arguments are drawn from civil engineering to the greatest extent possible, as a central means to help students engage with the material.

Operationalization: While adaptation might seem a fairly obvious integrative strategy, operationalization and embedding are perhaps more novel with respect to philosophy of science teaching. Operationalization for our purposes means that the knowledge and concepts imparted to students can be put directly into practice in the form of concrete analytical tasks (guided by sets of instructions). This helps ensure that students in a scientific or engineering programme can actively engage with philosophical notions in at least similar ways to which they engage with and learn (and learn the value of) scientific concepts. Operationalization has played two prominent roles in the current course design. Firstly elements have been selected not just for their relevance to civil engineering but also by virtue of their ability to be operationalized as concrete tasks. Millian causal reasoning is one example for which exercises are available (e.g. Kelley, 2013). Secondly various philosophical concepts and theories have been reconstructed in the course in terms of categories, questions and instructions which students can directly apply. For instance the paradigm concept, which in Kuhn's terms is outlined mostly in general and abstract terms (using for instance the concept of a disciplinary matrix), is re-represented in the course as a set of more concrete categories - namely, core problems, core values/goals, core concepts, core assumptions, core methods, theories and models, and core exemplars - each of which is defined for the students and examples presented using neoclassical economics which civil engineering students are at least peripherally familiar with. Using the examples students can then be shown how various elements in each category might relate to other elements of other categories resulting in a network of relations or dependencies. For example the core epistemic value of monetary quantification as the proper unit of measurement can be linked to a core concept of utility which can then be linked to the core assumption that agents maximize utility itself linked to the core methodology of constrained optimization. These operations help illustrate the relations between elements in the problem-solving system of economics but also the extent to which quantification is embedded within economics.

In the form of a project students are asked to apply these operations of categorizing and mapping to civil engineering sub-fields to understand the hierarchical structure of their own particular problem-solving systems. Students are asked to work in groups of 4 or 5 on a field or subfield relevant to their bachelor thesis. In the University of Twente bachelor programme students choose a thesis topic within either water management, traffic management or construction management, and usually 
share problem-solving frameworks on which they can collaborate, such as developing and applying large scale models in water system management which is now almost a dominant practice in the Netherlands. It is up to students how to identify a coherent problem-solving system which could qualify as a paradigm. Students are asked to fill out the categories, map some relationships, and then identify 1) the closed or bounded aspects of their fields and how this might make them resistant to certain types of innovations or 2) possible adjustments to the system which might expand the set of problems and their possible solutions the field might consider. For instance how might the incorporation of information from psychology change traditional model-based mathematical traffic engineering paradigms. While presenting paradigms in this way is not necessarily completely faithful to Kuhn's notion of paradigm and does not instruct students on the historical role of the paradigm concept in philosophical discussion (as the concept is often taught), it does allow students to actively apply the paradigm concept and perceive potentially at least a direct relevant to it in their own practice.

In addition to the paradigm task students are also asked to perform a model decomposition task - for a model relevant to their own work - based on Knuuttila and Boon (2011)(see also Boon, 2020). ${ }^{2}$ The purpose of this paper is to advocate for conceptualizing models principally as epistemic tools rather than as concrete representations. Models give us knowledge through dynamic processes of construction and modification rather than static similarity relationships. This framing focuses attention on more constructive or purpose-driven aspects model-building and model design, useful for training students to critically reflect on their own modeling decisions. Knuuttila and Boon provide a set of categories for decomposing a model into functional components; e.g. epistemic purpose of a model, problem context, measurable variables, the physical structure it models, background knowledge and principles, idealizations and assumptions, and modes of evaluation or justification. These categories can be readily operationalized in the form of a practical task which students can apply to the both help them analyze modeling choices in a modeling research paper (and see the rationale behind the decision made by modelers in those papers) or a model they are building. After performing the task students are asked to reflect on the extent to which those modeling choices were guided by functional goals, how they now perceive or understand the limitations or constraints on their modeling choices. Through these philosophical interventions students are encouraged to think of models less as "copies" of what they represent but rather as technologies or tools designed and optimized for specific goals.

Embedding: By "embedding" we refer here to the process of adapting the course structure and educational approach or philosophy to fit the educational context in which the course runs. This could require for instance examining the degree stage at which a philosophy course might be taught, and the activities and projects students are engaged in at the same time, and trying to link the course to these. It can also mean replicating the educational styles students are familiar with, so that there is ultimately continuity between a philosophy of science course and the other

\footnotetext{
${ }^{2}$ This task was first developed at the university by Mieke Boon.
} 
educational activities students are engaged in. Over the previous 5 years the civil engineering course has been adapted to fit the educational approaches employed in the civil engineering programme, many of which are common among modern engineering and scientific programmes, and the programme structure.

The most important aspect of programme structure guiding this philosophy of science course is the fact that it takes place within a module in which students are principally preparing and planning their bachelor thesis. This is the first and only point in their degree in which they engage in independent scientific research and the thesis is meant to be a generalizable scientific contribution rather than a purely engineering solution to a specific problem. With respect to embedding the philosophy of science course then the main strategy developed over the past 5 years is to engage as much possible with the thesis project. This means in practice framing assessment activities and tasks to intersect with the bachelor thesis. We have mentioned two of these already. Students are asked to do the paradigm task and B\&K task with respect to a paradigm and modeling study relevant to their thesis. And at other times during the course students are asked to provide reflections on how issues relate to their own projects. The third principal task is what is called the evaluation task, which students are asked to prepare after their theses are completed. Students are asked to evaluate their thesis project using analytic concepts from the course, and students are rewarded with respect to the depth and frequency with which they apply those concepts. They are asked to interpret the argumentative or logical structure of their research and evaluate the reliability and validity of their work, including it's scientific-ness, potential biases and other weaknesses. They are also asked more reflectively to assess the value of the kind of scientific research they engaged in to civil engineering generally. These moves overall are thus designed to embed the philosophy component as much as possible within the course of the civil engineering curriculum.

The other important aspect worked with in this course is to ensure that the educational styles and techniques are not radically distant from those used within the engineering programme itself and indeed to maintain as much continuity as possible. Simply confronting students who have never written essays or read substantial texts before with both kinds of tasks risks alienating many students unless a large but time-consuming effort is put into both motivating and developing the skills for doing so. In this current course large writing and reading tasks are limited. Effort has been made to adapt the course to fit the educational structures students are familiar with, in this case, task-based learning, and generally limited levels of difficult reading. Students are asked to read no more than 20 pages per session of "philosophical text" per seminar. The task-based learning aspects are represented in the numerous exercises students are required to do during the course, many of which have been mentioned already (e.g. logic tasks, causal reasoning tasks). The paradigm and B\&K tasks can also be understood this way. They are framed more in the style of a report rather than a critical or argumentative essay. At the same time in-class activities are interactive in the manner of much engineering education, involving frequent group activities.

Lastly it is worth mentioning that the elaboration of learning goals in terms of the concrete application of concepts (as in the paradigm case), which are then measured 
through such tasks, is in line with current scientific educational theory, particularly the importance of constructive alignment (Biggs, 1996)- namely ensuring alignment of learning goals with assessment procedures, which is considered fundamental for engineering education (Nightingale et al., 2007). A lack of concrete relations between learning goals and assessment can result in student uncertainty and dissatisfaction. However it can be a difficult standard for philosophy courses to achieve given relatively abstract learning goals (regarding say argumentation and conceptual analysis) that are hard to measure. Framing assessment less in terms of essay performance and more in terms of specific problem tasks while mapping those back to specific learning objectives helps ensure that there is strong constructive alignment in line with the expectations of current engineering students at the university. Learning goal 4 (see Table 1) for instance is directly assessed through the B\&K task. The paradigm task assesses learning goal 2.

Together these elements of adaptation, operationalization and course embedding, aim to integrate the philosophy of science course into the civil engineering programme, and avoid a philosophy course that stands out as somewhat anomalous on the curriculum. There is some evidence that students generally recognize the course as well-integrated and relevant to civil engineering, and a proportion can contemplate integrating course concepts into their future practice. At least some actually do so in the context of analyzing their Bachelor thesis. For example in a standardized university survey for 2018 the course was evaluated overall at 7.3 out of 10 by students (No. of responses $=24$; Response rate $=23.8 \%$ ) in its first iteration of the year (March-April) and 7.4 in the second iteration (September-October) (No. of responses $=17$; Response rate $=31.7 \%) .{ }^{3}$ RESTS courses are evaluated at 6.2 on average. For the question, "This RESTS education was well-integrated with the rest of the module, the average score was 3.7 out of 5 and 3.6 out of 5 for the two iterations. This suggests students agreed the course was meeting its integrative goals to a reasonable extent. ${ }^{4}$ A further survey sent out in July 2018 (No. of responses 16 out of 51), developed to study this question by the author for a teaching qualification, adds some support to this claim. Most students give the course a 6 to 8 on a 10 scale in terms of its relevance to civil engineering. On the relevance of the course to their bachelor thesis, most students answered 7 or 8 on a 10 scale. Students were evenly divided on whether the course would influence their practice (46\% Yes; $46 \%$ No).

As mentioned at the end of their bachelor theses students are required to write a report critically evaluating and reflecting on the scientific quality of their bachelor research. Students are reminded about the relevance of the philosophical concepts they learned earlier, but are not required to use those concepts. As part of the aforementioned teaching qualification the 2018 tasks were analyzed $(n=33)$ to test whether course concepts - paradigm; logical concepts \{induction; deduction;

\footnotetext{
${ }^{3}$ The university surveys students (via email) on all courses through a central office. Most questions are standardized for all courses, with some specific questions for RESTS courses, including their degree of integration.

${ }^{4}$ For comparison the STS course which has not pursued a highly integrative strategy received an overall grade of 5.5, and 3.3 and 3.4 in answer to the questions above in 2018.
} 
abduction\}; robust(ness); value(s); validation; bias; control; model concepts \{idealization; abstraction - were used in student analyses and how "well" or correctly the concept was used. The results showed that $70 \%$ of tasks used one of these course concepts at least once, and half of those were good uses.

These results are given here not as a strict validation of the course or the strategy. A single set of results with low response rates is limited in this respect. Results on individual questions may be biased by the performance of the teacher and the attitude the students might have towards other aspects of the course. No interrater reliability test was performed with respect to judgments of the use of concepts in the evaluation task. Further there is no direct information here on how the integration and relevancy results correlate with concept use. Nonetheless these results are an indication students do not at least disagree with the integrative and relevancy intentions of the course or perceive these course intentions differently. The degree to which students are willing to integrate concepts into their practice measured through their future intentions and their evaluation tasks may seem low, but given the historical difficulties of convincing students and others of the relevance to actual practice, these results can also be interpreted positively. They do at the least help establish a baseline for future uses of this or any other integrative strategy.

\section{Limitations and challenges of implementation}

Empirical results aside however, there are a family of issues instructors should consider when implementing this kind of integrative strategy. Putting this specific design into practice is not without obstacles and difficulties and these understandably may dissuade instructors from undertaking such an intensive course design project. The specific education context at the University of Twente with its dedicated RESTS programme has afforded opportunities to engage with individual programmes, opportunities which might not be readily available at other institutions, particularly where there are limited philosophy of science staff and an obligation to instruct the entire science and engineering community. However if the pay-off in terms of achieving actual integration of philosophy of science into a specific curricula is seen as large enough, and the goals of impacting scientific practices are important enough, then there should be incentives for philosophers of science to reach out to individual programmes and lobby for more tailored integrated courses for specific fields.

That said philosophy of science may not be relevant for students in fields who are engaging in no empirical work and as such the subject of scientific reasoning, even when situated in discussion about modeling, will be seen as unhelpful. A similar course developed for applied mathematicians by the author (at the same university) for 3rd year students has been less well accepted-according to student surveys and written students responses from 2016 to 2018 - insofar as applied mathematics students mostly have mathematical proof tasks for their bachelor theses and students struggle to see the broader relevance to them of discussing scientific issues, even when they relate to models, for those tasks. In addition some other subjects seem relatively rigid in their practices and do not seem to require much scientific 
decision-making or reflection from the students themselves despite relying in principle on scientific methodology. This is the experience of teaching philosophy of science through the RESTS programme to electrical engineers, and industrial and engineering management (IEM) students, again in the context of their bachelor thesis preparation modules. Both groups have relatively fixed methodological strategies and protocols, which students are trained to operate. In electrical engineering the theory on which their approaches are developed is well-established and can be operated without raising any empirical issues or concerns. In the case of IEM one might argue there is an overreliance on protocols and problem-solving devices at the expense of independent thinking. There are thus general reflective points to be made. But in neither case does this help students with their bachelor thesis, and in general both fields have limited hooks for engaging philosophy of science in a way that would seem relevant or useful to them. As such it is perhaps worth acknowledging that philosophy of science is likely not always beneficial or important for all and every technical group, and as philosophers of science we should be careful not to overestimate our relevance and importance.

Philosophers of science involved in scientific education may object to these conclusions, and indeed pursuing this kind of design may seem problematic insofar as these course designs may misrepresent some of the fundamental elements of what philosophy of science is and offers, 1) by simply choosing bits and pieces that are suitable for individual programmes, 2) by largely leaving to the side what might actually be considered central to philosophy overall - namely styles of critical reasoning and argumentation. With respect to the former one can hold to the position that philosophy of science needs to be taught holistically, as it often is in philosophy programmes, as a set of cumulative debates and discussions on particular subjects, which often follows each other historically. It is only by going through these in progression that students can possibly acquire a deep insight into the philosophical questions and concerns of philosophy of science, and how our insights into science were developed and corrected. Many philosophy of science textbooks stick to this kind of organization, with the goal of giving students a both deep and encompassing overview of core philosophy of science discussions starting with say the problem of induction. Without presenting this core body of knowledge philosophy of science risks losing its identity and status as an independent body of thought with its own goals and agenda. On this view training argumentation and conceptual analysis is central to what philosophy has to offer, and can provide scientists and engineers a particular set of skills that no other field can (see Siegel, 1989). These skills operate at a meta-level and at least over a longer term could improve the rigour and depth of scientific reasoning.

The motivations and reasoning behind such views are certainly reasonable. Other groups within RESTS at the University of Twente are certainly less enthusiastic with respect to integration the extent to which trying to contribute directly to the scientific objectives of engineering programmes undermines the integrity of what they are teaching. They reject in other words instrumentalization of their fields to fit their particular educational and scientific agenda. The fact that philosophy of science can be somewhat instrumentalized in our case speaks positively with respect to the way many philosophers of science do think about their subject. However it is true that 
within the integrative course design strategy suggested here students do not leave the course with a strong understanding of the philosophy of science corpus or with necessarily better argumentative or conceptual analytic skills.

This all said, these views on the role of philosophy have, arguably, less tangible outcomes, and if our goal for philosophy of science teaching is to have direct impact on scientific practices then there are reasons to be skeptical of the ability of these less integrated approaches, and to prefer as much integration as possible.

\section{Conclusion}

This paper has introduced an integrative course design strategy for teaching philosophy of science based on adaptation, operationalization and embedding of philosophical concepts within scientific and engineering curricula. By doing so the goal has not been to invalidate or displace other approaches. Rather the goal has been to illustrate a potential set of means for thinking about how to approach the complicated challenge of increasing the uptake of philosophical concepts into scientific practice by students, and the issues this raises with respect to what we think philosophy should impart to students and whom we should aim to teach. It is also worth reflecting that engaging in this kind of design strategy has other benefits other in this respect, since it can help us as philosophers of science reflect on the generality and applicability of philosophy of science, and the degree to which it does and can meet its objective of producing insights relevant to scientific practice. Implementing this course design strategy forces one to confront the relevance (and generalizability across different disciplines) of our philosophical concepts directly and expose them to some kind of testing at least, a process which can ultimately improve our concepts. And while it can be hard convincing practicing scientists and engineers to pick up and apply philosophical ideas, education does provide a ready opportunity.

\section{Declaration}

Conflict of interest None.

Ethical approval None required.

Informed consent None required-All data collected is anonymous survey data.

Open Access This article is licensed under a Creative Commons Attribution 4.0 International License, which permits use, sharing, adaptation, distribution and reproduction in any medium or format, as long as you give appropriate credit to the original author(s) and the source, provide a link to the Creative Commons licence, and indicate if changes were made. The images or other third party material in this article are included in the article's Creative Commons licence, unless indicated otherwise in a credit line to the material. If material is not included in the article's Creative Commons licence and your intended use is not permitted by statutory regulation or exceeds the permitted use, you will need to obtain permission directly from the copyright holder. To view a copy of this licence, visit http://creativecommons.org/licen ses/by/4.0/. 


\section{References}

Barker, G., \& Kitcher, P. (2014). Philosophy of science: A new introduction. Oxford University Press.

Beder, S. (1997). Technological paradigms: The case of sewerage engineering. Technology Studies, 4(2), 167-188.

Biggs, J. (1996). Enhancing teaching through constructive alignment. Higher Education, 32(3), 347-364.

Boon, M. (2020). Scientific methodology in the engineering sciences. In D. P. Michelfelder \& N. Doorn (Eds.), The Routledge handbook of the philosophy of engineering (pp. 80-94). Routledge.

Kelley, D. (2013). The art of reasoning: An introduction to logic and critical thinking. WW Norton \& Company.

Knuuttila, T., \& Boon, M. (2011). How do models give us knowledge? The case of Carnot's ideal heat engine. European Journal for Philosophy of Science, 1(3), 309-334.

Grayson, D. J. (2006). Rethinking the content of physics courses. Physics Today, 59(2), 31.

Grüne-Yanoff, T. (2014). Teaching philosophy of science to scientists: Why, what and how. European Journal for Philosophy of Science, 4(1), 115-134.

Höttecke, D., \& Silva, C. C. (2011). Why implementing history and philosophy in school science education is a challenge: An analysis of obstacles. Science \& Education, 20(3), 293-316.

Morgan, M. S., \& Morrison, M. (1999). Models as mediators. Cambridge University Press.

Newberry, B. (2010). Katrina: Macro-ethical issues for engineers. Science and Engineering Ethics, 16(3), 535-571.

Nightingale, S., Carew, A.L., and Fung, J.. (2007). Application of constructive alignment principles to engineering education: Have we really changed?. In: Proceedings of the 2007 Australasian association for engineering education conference, Melbourne.

Siegel, H. (1989). The rationality of science, critical thinking, and science education. Synthese, 80(1), $9-41$.

Wimsatt, W. C. (2007). Re-engineering philosophy for limited beings: Piecewise approximations to reality. Harvard University Press.

Woodward, J. (2005). Making things happen: A theory of causal explanation. Oxford University Press.

Publisher's note Springer Nature remains neutral with regard to jurisdictional claims in published maps and institutional affiliations. 